\title{
Cancer risk from exposure to alpha emitters: a view from the ICRP
}

\author{
Margot Tirmarche ${ }^{1}$, Dominique Laurier ${ }^{2}$, A. Iulian Apostoaei ${ }^{3}$, Eric Blanchardon ${ }^{2}$, \\ Elizabeth Ellis ${ }^{4}$, Ethel Gilbert ${ }^{5}$, John D. Harrison ${ }^{6}$, Jean-François Lecomte ${ }^{2}$, James $W$. \\ Marsh $^{6}$, François Paquet ${ }^{2}$, Mikhail Sokolnikov ${ }^{7}$, Richard Wakeford ${ }^{8}$, and Sergei Zhivin ${ }^{2,9}$ \\ ${ }^{1}$ Autorité de Sûreté Nucléaire (ASN), Chatillon, France \\ ${ }^{2}$ Institut de Radioprotection et de Sûreté Nucléaire (IRSN), Fontenay aux Roses, France \\ ${ }^{3}$ Oak Ridge Center for Risk Analysis, Inc., Oak Ridge, TN, USA \\ ${ }^{4}$ Oak Ridge Associated Universities, Oak Ridge, TN, USA \\ ${ }^{5}$ National Cancer Institute (NCI), Rockville, MD, USA \\ ${ }^{6}$ Public Health England, Centre for Radiation, Chemical and Environmental Hazards, Chilton, UK \\ ${ }^{7}$ Southern Urals Biophysics Institute (SUBI), Ozyorsk, Russia \\ ${ }^{8}$ Centre for Occupational and Environmental Health, University of Manchester, Manchester, UK \\ ${ }^{9}$ Institut national de la santé et de la recherche médicale (Inserm), Villejuif, France
}

A significant number of new results have been published since 2000 from epidemiological studies addressing the risk of cancer associated with internal exposure to radionuclides emitting alpha radiation. The International Commission on Radiological Protection (ICRP) mandated a task group (TG64) to review these results and evaluate their their implications for the protection. TG64 is composed of members from ICRP Committees 1 and 2, as well as external experts with epidemiologic and dosimetric expertise.

The alpha-particle emitting radionuclides considered were radon-222 and its decay products, plutonium-239 and isotopes of uranium.

The presentation will summarize the current state of knowledge regarding cancer risk associated with radon, plutonium and uranium. The main conclusions reached in relation to radon have already been published [1], and will be put in context with the recently published radon dose coefficients [2]. Results obtained on cancer risk associated with plutonium or uranium exposures will be summarized, and current work of TG64 on lifetime risk estimates presented in details. In addition, the lifetime lung cancer risks from inhalation of plutonium are compared with the corresponding risks from low-linear energy transfer (low-LET) radiation, which provides some indication of possible values of the relative biological effectiveness (RBE) of alpha particles for the induction of lung cancer.

\section{References}

1. M. Tirmarche, J.D. Harrison, D. Laurier, F. Paquet, E. Blanchardon, J.W. Marsh. Lung Cancer Risk from ICRP Publication 115: Radon and Progeny and Statement on Radon. Ann. ICRP. 40, 1 (2010).

2. F. Paquet, M.R. Bailey, R.W. Leggett, J. Lipsztein, J.W. Marsh, T.P. Fell, T. Smith, D. Nosske, K.F. Eckerman, V. Berkovski, E. Blanchardon, D. Gregoratto, J.D. Harrison; 
Authors on Behalf of ICRP. ICRP Publication 137: Occupational Intakes of Radionuclides: Part 3. Ann. ICRP. 46, 1 (2018). 